\title{
The Application of PLC in the Auto-control System of Chemical Makeup Water Treatment of Boiler
}

\author{
Zheng Lai \\ College of Electronic Science and Engineering \\ Jilin University \\ Changchun 130012, China \\ E-mail: laizheng@email.jlu.edu.cn
}

\begin{abstract}
With the deepening of China modernization course, the application of Programmable Logic Controller (PLC) is used more and more abroad in China. This article adopted the Quantum PLC and iFix industrial configuration software to study the application of PLC in the auto-control system of chemical makeup water treatment of boiler.
\end{abstract}

Keywords: Chemical water treatment of boiler, PLC, Application

\section{Chemical water treatment of boiler}

Because the boiler is developed to the trend of large size, high temperature and high pressure, so the requirement of water quality for the boiler makeup water is higher and higher, and that needs to almost get rid of all salts in the water. So anion-cation exchange technology has been developed quickly. For example, use the $\mathrm{H}$ cation exchanger to exchange various cations in the water and give out $\mathrm{H}^{+}$, and use $\mathrm{OH}$ cation exchanger to exchange various anions in the water and give out $\mathrm{OH}^{-}$. Through the exchange treatment of anion-cation exchanger, all salts in the water will be basically ridded. This method is called water chemical salt ridding treatment. When the raw water gets across the cation exchanger, cations such as $\mathrm{Ca}^{2+}, \mathrm{M} \mathrm{g}^{2+}, \mathrm{K}^{+}$and $\mathrm{N}^{\mathrm{a}+}$ in the water will be absorbed by the exchanger and commutative $\mathrm{H}^{+}$ on the exchanger will be replaced to the water, and create corresponding inorganic acid with anions in the water. This sort of cation exchanger is also called as the cation-bed.

When the water with inorganic acid gets across the anion exchanger, anions such as $\mathrm{SO}_{4}{ }^{2-}, \mathrm{Cl}^{-}$and $\mathrm{HCO}^{3-}$ in the water will be absorbed by the exchanger, and the commutative $\mathrm{OH}^{-}$on the exchanger will replaced to the water and combine with $\mathrm{H}^{+}$in the water to compose $\mathrm{H}_{2} \mathrm{O}$. This sort of mixed ion exchanger is also called as mixed-bed.

When the resin in the mixed bed is disabled, the anion resin and cation resin will be separated first and regenerated respectively afterward.

Because the use quantity of boiler makeup water is large and the requirement of water quality is high, so the mixed bed salt ridding treatment is always used in series after 1st class salt ridding system to further purify the water quality.

Anti-infiltration is a sort of new membrane separation technology and a sort of process which depends on the anti-participation membrane to separate the solvent and solute in the liquor under the pressure.

The so-called "infiltration" is a sort of physical phenomenon. When separate two sorts of water with different concentration salts by a piece of half-infiltrative membrane, the water with lower salts will infiltrate to the water with higher salts through the membrane, but the salts will not be infiltrated, so the salt concentrations will be amalgamated until the concentrations are equal. However, this process needs long time, so this process is also called as natural infiltration. If add a pressure on the side with higher salt concentration, it will stop the above infiltration, and this pressure is called as infiltration pressure. If the pressure is increased, it will make the water infiltrate to the opposite direction and leave the salts. Therefore, the anti-infiltration salt ridding treatment is to inflict more pressures than the pressure of natural infiltration to make the infiltration implement to the opposite direction, and press the water molecule in the raw water to the other side and create clean water and achieve the intention getting rid of salts in the water.

\section{Control principle and composing configuration of program control system}

The whole control system is composed by locale measurement meters (including electric meter, thermal meter and component analysis meter), electromagnetic valve chest and computer system.

\subsection{Control principle}

The control system adopts the form of PLC controller + CRT upper monitor, i.e. on the one hand, PLC controller can communicate with the upper computer through $\mathrm{DH}+$ network, send the computed and treated transmittal data to display 
on the upper computer and accept the control instruction from the upper computer, on the other hand, PLC controller communicate through the remote $\mathrm{I} / \mathrm{O}$ scanner and the $\mathrm{I} / \mathrm{O}$ module of remote computer frame, receive signals returned from the locale and send out control instructions, and drive local equipments through control logic. The upper monitor sends out operation instruction, exports various instructions from the upper monitor to the locale equipment through logical operation of PLC controller, and uploads work parameters such as water quality parameter, flux, pressure, temperature, liquid position and operation state of the equipment at the present time to display on the upper monitor.

\subsection{Configuration of hardware}

The core of PLC is CPU which has functions of memory and logical operation and likes as human brain. It inputs the data collected on the locale to CPU through the input module, transmits the information needed by the control objective through artificial compilatory trapezium logical control figure to the output module by CPU, and automatically control the equipment through the output points of the output module.

The input module is divided into analog input module (AI) and digital input module (DI). The analog signals of 4 20mA such as flux, electric conductivity, acid-base concentration are transmitted to AI. The feedback signals of valves and pumps are generally transmitted to DI. The output module is divided into analog output module (AO) and digital output module (DO). The feed quantity of the feed equipment is adjusted by the points of AO, and the valves and pumps are controlled by the points of DO.

The reconstruction of the trunk network of chemical water treatment control system adopts the star network and Quantum PLC and two sets of iFIX operation stations (one is also the engineer station) which are connected with exchanger to compose TCP/IP Ethernet, and this network is easy to be used, configured and extended. The whole control system includes 3 sets of control computer chests (I/O computer chest) and 1 set of power distribution chest (including $380 \mathrm{~V} / 110 \mathrm{~V}$ AC transformer and dual power supply switch equipment). The control system PLC belongs to Quantum products made by Schneider Company, which controls the automatic regeneration, half-automatic regeneration and manual regeneration of the chemical water treatment system, and the configuration table of I/O point is seen in Table 1.

The concrete listing of PLC configuration includes following contents.

(1) The CPU of PLC adopts the Quantum53414A of Schneider Company, and its processor is 32 bits and its EMS memory is $4 \mathrm{MB}$.

(2) DI adopts 32 points module 140DDB5300, 24VDC and 4 groups of insulation.

(3) DO adopts 32 points voltage output module 140DDO353000, 24VDC, and the capacity of every channel is $0.5 \mathrm{~A}$.

(4) AI adopts 16 points module $140 \mathrm{ACI} 0400$ and the signals of 4 20mA.

(5) AO adopts 8 points module 140ACO13000 and 4 20mA.

(6) Configure with a piece of TCP/IP Ethernet communication port module 140NOE77100.

(7) This PLC is the newest product, and the module of CPU has main frequency of $96 \mathrm{MHz}$ and user logic memory of $1 \mathrm{M}$.

The monitor computer adopts DELL P4/3.0G CPU, 512M EMS memory, 21 inch high differentiation color LCD which can offer clear, high contrast, high definition figures and tables that are easy to be read by operators (definition 1600× 1200 image), and multimedia anti-magnetic sound box. And the exchanger adopts the products of Hirschmann.

\subsection{Configuration of software}

The program software adopts Concept V2.5 which supports five program languages of IEC1131-3 including standard sequence flow chart, function chart, trapezium chart, structured text and instruction list. Because of the characters of chemical water treatment technology, most controls are sequence controls, and adopt convenient and applied SFC sequence flow chart.

The configuration software adopts iFIX V3.5, and communicated with Quantum PLC by the driver of MBE. At the same time, combining with PLC control program, it can realize following functions.

(1) Display the operation of system equipment and display the parameters of operation.

(2) Set up program control step sequence.

(3) Display the fault and warning of system equipment.

(4) Inquire operation report forms, operation records, historical curves and accident records.

\subsection{Electromagnetic valve chest}

In the actual operation and regeneration processes of the program control system, except for necessary interlock control, the control systems of the activated carbon filter, cation bed, middle water tank, salt ridding water tank, anion bed, 
acid-base measurement system are respectively a relative independent system, so one electromagnetic valve control chest is equipped around every bed body, and the operation of knobs on the control panel can operate various valves of the bed body. When the automatic position is selected, the instruction of PLC will control the valves through the switch valve in the electromagnetic valve chest, and the program control system is equipped 7 spot electromagnetic valve chests.

\subsection{Locale measurement meters}

To ensure the operation and regeneration of water treatment, the program control system equips corresponding meters to the real-time measure various main parameters and the configuration of meters are seen in Table 2 .

\section{Conclusions}

According to the actual statistics, the technology of water treatment directly decides the normal operation of industrial equipment, and many tube explosion accident of industrial boiler were induced by bad water quality. With the enhancement of industrial automatization level and the extensive application of computer in the operation management domain, the computer monitor technology is highly regarded in the domain of water treatment. The water treatment monitor system integrates inspection online, fault diagnosis, computer management, assistant decision and other technologies, which largely enhances the automatization degree of water treatment, and reduces faults of manual factor, and further increase the water saving efficiency.

Using the technology principle of water treatment and the data collection of sensor, the application of PLC in the auto-control system of chemical makeup water treatment of boiler not only can contribute the management of industrial water making, but can properly adjust the technical parameters according to the water quality to make system pressure stable, equipment operation stable, fault ratio largely reduced, and water making cost reduced to large extents. Through this system is still in the perfection stage, but the actual application has important meanings to enhance the reliability of the operation, and this system has high economic benefits and social benefits, large research and development potentials and application foreground.

With the deepening of China modernization course, the application of Programmable Logic Controller (PLC) is used more and more abroad in China. China should expedite the research and development of PLC products and the cultivation of talents to make various industries can expertly grasp the technology of PLC and drive the development of China economy.

\section{References}

Chang, Dounan. (2002). Principle, Application and Experiment of PLC. Beijing: China Machine Press.

Chinese Society of Power Engineering. (2002). Technical Manual of Fuel-Burning Power Plant Equipments. Beijing: China Machine Press.

Liao, Changchu. (2002). Programming and Application of PLC. Beijing: China Machine Press.

Li, Peiyuan. (2000). Water Treatment and Water Quality Control for Thermal Power Plant. Beijing: China Power Press. Liu, Zhiyuan. (1999). PLC and Its Application in the Power Plant. Beijing: China Power Press.

Song, Deyu. (2005). Design Technology of PLC Principle and Application System. Beijing: Metallurgical Industry Press.

Tian, Ruiting. (1994). Application Technology of PLC. Beijing: China Machine Press.

Wang, Tingyou. (2005). Principle and Application of PLC. Beijing: National Defense Industry Press.

Wang, Weibing. (2002). The Principle and Application of PLC. Beijing: China Machine Press.

Wang, Zhaoyi. (1993). Tutorial of PLC. Beijing: China Machine Press.

Yu, Qingguang. (2001). Applications of Programmable Logic Controller (PLC) in Large Scale Thermal Power Plant. Chinese Journal of Scientific Instrument. No. 22(3).

Zhou, Weidong. (1999). Auto-control Technique for Chemical Feed Water Treatment of Boilers. Hubei Chemical Industry. No. 16(6). 
Table 1. Configuration table of I/O points

\begin{tabular}{|l|l|l|l|l|l|}
\hline & DI & DO & AI & AO & Total \\
\hline Actual use & 370 & 299 & 51 & 8 & 728 \\
\hline Actual configuration & 416 & 352 & 64 & 12 & 848 \\
\hline Provided quantity of module & 13 & 11 & 4 & 3 & 31 \\
\hline Point quantity of every module & 32 & 32 & 16 & 4 & 84 \\
\hline
\end{tabular}

Table 2. Configuration of measurement meters

\begin{tabular}{|c|c|c|c|}
\hline Meter name and type & Factory & Quantity & Purpose \\
\hline $\begin{array}{l}\text { EJA pressure flux } \\
\text { transducers }\end{array}$ & $\begin{array}{l}\text { Chengdu Henghe } \begin{array}{r}\text { Chuanyi } \\
\text { Electromechanical Equipment } \\
\text { Co., Ltd }\end{array} \\
\end{array}$ & 24 & $\begin{array}{l}\text { Be used to monitor input/output fluxes and } \\
\text { backwash fluxes of various bed bodies and } \\
\text { regeneration systems }\end{array}$ \\
\hline $\begin{array}{l}\text { Static pressure level } \\
\text { meter- YU } 21\end{array}$ & $\begin{array}{l}\text { Wuhan Guangming Meter } \\
\text { Factory }\end{array}$ & 3 & $\begin{array}{l}\text { Be used to monitor liquid positions of salt } \\
\text { ridding water tank and middle water tank }\end{array}$ \\
\hline $\begin{array}{l}\text { Electric conductivity } \\
\text { meter- } 9782 \mathrm{C}\end{array}$ & HNOEYWELL & 4 & $\begin{array}{l}\text { To monitor water qualities of various bed } \\
\text { bodies and take them as the proof to judge } \\
\text { whether the bed body is disabled }\end{array}$ \\
\hline $\begin{array}{l}\text { Micro natrium meter- } \\
079721-2\end{array}$ & HNOEYWELL & 1 & $\begin{array}{l}\text { To monitor the operation of cation bed and } \\
\text { take it as the proof to judge whether the } \\
\text { cation bed is disabled }\end{array}$ \\
\hline PH meter- 9782PH/ORP & HNOEYWELL & 3 & $\begin{array}{l}\text { To monitor the water quality of salt ridding } \\
\text { water and neutralization pool waste water } \\
\text { treatment }\end{array}$ \\
\hline Acid-base meter- 9782 & HNOEYWELL & 4 & $\begin{array}{l}\text { To monitor the concentration of regeneration } \\
\text { liquid when the cation bed and anion bed are } \\
\text { regenerated }\end{array}$ \\
\hline $\begin{array}{lr}\text { Magnetic reversible } \\
\text { level } \\
\text { UHZ257-57/C }\end{array}$ & Shanghai Yuanwang & 10 & $\begin{array}{l}\text { Be used to monitor the liquid position of } \\
\text { various liquor tanks of mordant acid-base } \\
\text { measurement system }\end{array}$ \\
\hline
\end{tabular}

